\title{
Attitude Change in a Realistic Experiment: The Effect of Party Membership and Audlence Reaction During an Interview With a Dutch Politician ${ }^{1}$
}

\author{
O. WIEGMAN ${ }^{2}$ \\ University of Twente, The Netherlands
}

\begin{abstract}
In this realistic experiment, an interview with the leader of the Liberals in the Dutch Parliament was recorded in the presence of a live audience, which reacted in a positive, negative, or neutral way. It was shown to subjects of two opposing political parties, whose attitudes were to be changed by the experimental interview. The main hypothesis, which predicted more attitude change in the positive than in the negative audience condition, could not in general be supported. The alternative audience attraction hypothesis was mainly sustained: With an audience, perceived as attractive, attitude change was greatest when the audience reacted positively and least when it reacted negatively, while for an unattractive audience the opposite effect was demonstrated.
\end{abstract}

This realistic experiment is the continuation of a former study (Wiegman, 1985) in which the leader of the Socialists in the Dutch Parliament and his Liberal opponent participated. In that study, completely identical experimental television interviews on a certain political topic were made with both political leaders, who at the request of the experimenter used exactly the same words and defended the same point of view. A video recording of these interviews was subsequently shown to members of the Socialist and Liberal parties and attitude change was measured. The content of the political topic was based on Zucker's (1978) two criteria. Zucker demonstrated that the direct influence of the media is greatest when the issues fulfills two criteria. First, the issue must not relate directly to the personal experience of the recipient; and second, the issue should not have had extensive news coverage.

In the former study, we showed that both experimental television interviews with the Socialist and Liberal leaders led, in themselves, to attitude change: On all seven subject issues, opinions had changed as a result of the program. Support was also found for a second hypothesis: Attitude change being greatest for the attractive source of the subject's own party than for the less

\footnotetext{
I This article is part of an extensive study published in Meningen en Media by $O$. Wiegman, A. de Roon, and T. Snijders (1981, Van Loghum Slaterus, Deventer).

${ }^{2}$ Requests for reprints should be sent to Prof. Dr. O. Wiegman, Head of the Department of Psychology, University of Twente, P.O. Box 217, 7500 AE Enschede, The Netherlands.
} 
attractive source of the opposite party. An initial discrepancy between the Socialist and Liberal subjects was shown in their attitudes on six of the seven subtopics. We found significantly more attitude change on those topics in which the initial discrepancy was greatest.

The research reported here explores the effect of a reacting audience, present during a television interview with a politician, on the attitudes of subjects who were exposed to both the interview and the audience reactions. In this realistic experiment, it is not our intention to test new theories and hypotheses, but to explore in a naturalistic setting scientific and common sense notions which already exist. This realistic setting (in how many psychological experiments real politicians participated?) has its strengths but, as you will know, also its weaknesses. In this experiment, the identical political topic, discussed in exactly the same words, was used as in Wiegman (1985). Mr. Wiegel, leader of the Liberals in the Dutch Parliament at the time, and later Vice Premier, participated in our study. Television interviews were held with Mr. Wiegel in the presence of a reacting audience. A video recording was subsequently shown to members of the Socialist and Liberal parties, and attitude change was measured. The politician was interviewed in a television studio by a professional television team. It was not a spontaneous interview, but was planned so that the politician answered the questions in line with the experimenter's wishes. The studio audience was not spontaneous either, but reacted in three different ways to the politician according to the experimenter's instructions. In one condition, they reacted positively to the politician's argument; in a second condition, with the identical interview they reacted negatively; and in a third condition, they reacted in a neutral way.

We assume that the audience is a mediating factor between the source and the receiver. For example, Bennett (1955) found evidence indicating that the influence of a group on a person's opinion is, in part, mediated by his perception that other group members approve of the opinion being advocated. Other evidence is given by Duck and Baggaley (1975). The subjects in their study watched a television interview with a speaker in the presence of an audience reacting negatively or positively. It was found that the viewers perceived the source's expertise to be higher after he had addressed the positive audience. There is much evidence indicating that subjects exposed to a high-expert-source exhibit more attitude change than persons exposed to a low-expert-source (e.g., Aronson \& Golden, 1962; Horai, Naccari, \& Fatoullah, 1974; Hovland, Jinis, \& Kelley, 1953). Thus, the main hypothesis that will be tested is that positive audience reactions will increase the source's expertise and lead to more attitude change and that negative reactions will reduce the source's expertise, producing less attitude change in the intended direction. Neutral audience reactions will produce an intermediate effect.

Landy (1972) formulated an alternative hypothesis which we will call 
here the "audience attraction hypothesis." Landy postulated that, besides the reactions of the audience, the nature of the relation between the members of a reacting audience and the subjects whose attitudes are being assessed is also important. This audience can be perceived as being attractive or unattractive. Landy considered attractiveness as being primarily an ingroup-outgroup variable (see also Kelly \& Woodruff, 1956). An audience, which in the eyes of the subject belongs to his own group, is considered as a positive reference group and is perceived as attractive, whereas an outgroup is perceived as a negative and unattractive reference group. Landy postulated that both attractiveness and audience reactions are important in changing attitudes and predicted the following interaction effect: Subjects who hear an attractive audience approving a persuasive communication will manifest greatest attitude change in the direction advocated by the speaker, and change will be least when the attractive audience expresses disapproval. In subjects, however, to whom an audience is unattractive, attitude change will be greatest when the audience expresses disapproval and least when the audience expresses approval. In Landy's experiment, this hypothesis could not be supported. Instead he reported that, independently of the reactions of the audience, the opinion change for subjects in the attractive audience conditions was significantly greater than that of subjects in the unattractive audience condition. This was so even though subjects were led to believe that the source was unaware of the identity of the audience attending to his comments or of the audience's reactions. However, no significant interaction effect was found in relation to either attitude change or evaluation of the source, nor did the reactions of the audience produce a main effect.

We may ask why Landy found no evidence for his hypothesis. One of the reasons may have been that the experimental situation was too artificial. Before the experiment started, the subjects were informed either that the audience in the studio were fellow students (attractive) or members of a Nazi party (unattractive). Furthermore, they were told that the reactions of the audience had been added later as there had been no live audience present during the interview. Moreover, the source in Landy's experiment was a completely unknown person. Therefore there were several reasons to assume that the subjects might have become suspicious and resisted the influence of the experimental manipulations (cf. Wiegman \& Delfos, 1979).

Our study aims to test both our main hypothesis and Landy's audience attraction hypothesis, using a realistic experimental design. Thus, we had a well-known politician presenting a case in front of a live audience. We varied the reactions of the audience; but in the interest of realism, we did not tell the subjects to which political party the audience belonged. Instead, at the end of the experiment the subjects were asked to which political party they thought the audience belonged. When they responded that the audience belonged to 
their own party, which can be considered as an ingroup, we assume that the audience is attractive. When they responded that the audience belonged to a different party (outgroup), then it was labelled as unattractive. This gave us a basis to test the alternative audience attraction hypothesis by internal analysis.

\section{Method}

\section{The Experimental Television Program}

As already mentioned, Mr. Wiegel, the leader of the Liberals in Parliament, took part in the television interview. The topic chosen was the establishment of a second national airport in the Markerwaard area. The practical reasons for this choice of topic were that neither the politicians nor the political parties in Holland had, at the time of the study, taken a stand on the issue, so that the opinions expressed in the experimental interviews would not be at variance with current political thinking and would not be discredited on these grounds. Theoretically, the issue satisfied the following conditions. First, in a preliminary study it was found that subjects had a distinctly neutral opinion on the issue and that involvement was average, so that basically attitude change in either direction was possible (cf. Nemeth \& Endicott, 1976). Second, the topic met Zucker's two criteria: The subjects had no direct personal experience of the topic, because no such national airport existed, and, as was shown in our preliminary press analysis, the issue had rarely been in the news.

The experimental television interviews were produced by a professional television team from the Dutch television company VARA. The program was introduced by the chief editor of VARA's "Behind the News" and afterwards the well-known interviewer, Joop Daalmeyer, appeared on the screen and put eight questions to the politician. Mr. Wiegel answered the questions in a way that had been arranged beforehand. The politican advocated the establishment of a second national airport. He stated that the extension of Amsterdam's airport was out of the question, that none of the other regional airports was capable of extension, that increased noise levels at Amsterdam's airport were insupportable, that the choice of the Markerwaard area was best from an economic standpoint, that a decision had to be taken as soon as possible, and that the Markerwaard option represented the least costly solution.

The audience consisted of 45 men and women aged 20 to 60 years. The audience had been told by the researcher beforehand what was expected of them. During one interview (the positive audience condition), the audience had to react in a positive way to the answers of the politician. At particular points they applauded. We also recorded more subtle indications, such as gestures, nods, and sounds of approval which implied that the audience 
agreed with the speaker. During a second interview (the negative audience condition), boos, whistles, and sneering remarks were heard; and facial expressions were recorded, such as shaking of heads, frowning, and knowing smiles.

In the third interview (the neutral audience condition), the public reacted neutrally to Wiegel's case and behaved as interested bystanders. It should be noted that in all three versions Wiegel was also in the picture during the shots of the audience, in order to make the program more convincing to the viewer. So, the viewers saw Wiegel addressing himself to a live audience. Each of the three interviews lasted about 15 minutes.

\section{Attitude Measurements}

We measured not only the attitude towards the main issue, namely, the establishment of a second national airport, but also attitudes toward six related issues arising from the politician's arguments: That is, the Markerwaard as the appropriate location, the pressure for a quick decision, the increase in air traffic, the objection towards increasing the load on other airports, noise pollution, and the unfeasibility of extending Amsterdam's airport.

Attitude was measured according to Fishbein's method (Ajzen \& Fishbein, 1980; Fishbein \& Ajzen, 1975). A number of statements were offered covering all the issues mentioned above and the subject was asked whether these statements agreed with his own opinion. Moreover, questions were asked about the reacting audience with respect to correctness, sympathy, and pleasantness as measured on 7-point Likert scales.

In order to test the audience attraction hypothesis, we also asked the subjects to indicate to which political party the audience belonged. We considered the audience as being attractive when the subjects indicated that the audience belonged to their own political party and as unattractive when the subjects indicated it belonged to another party. It should be explained that the attraction of the audience is meant here and not the attraction of the source.

\section{Design and Subjects}

The study was carried out at party meetings. Two hundred seventy-six Socialists and 238 Liberals took part. First, they watched one of the experimental interviews on a video recorder and then completed a questionnaire. A $2 \times 5$ design contained the following factors: Party membership of the subjects (liberal-socialist) and audience reactions (positive, negative, neutral, no audience in the studio), and one control condition, in which the subjects did not see any television interview. The subjects were randomly assigned to 
the conditions by distributing cards of five different colors in a random order-one for each condition-to the participants of the meetings as soon as they entered the building.

\section{Results}

\section{Checking the Experimental Manipulations}

Because subjects of the same political parties as in our previous study (Wiegman, 1985) participated, we first wanted to establish whether the attitude scores in the present study are comparable to former results. On this occasion, a significant difference in attitude was found in the control groups between the Socialist and Liberal subjects (multivariate analysis of variance: $F=6.40, d f=1 / 122, p<.001)$.

Table 1 shows that in four cases the Liberals had higher attitude scores (a high score means low discrepancy) and in three cases the Socialists scored higher. This is exactly in correspondence with our previous results.

We also wanted to know how the viewers perceived the audience with respect to correctness, sympathy, and pleasantness, as measured on 7-point Likert scales. It was found that on all three scales together there was a significant difference between the three audience conditions (multivariate analysis of variance: $F=20.39, d f=6 / 532, p<.001$ ). In a univariate anal$y$ sis of variance, a significant difference was found for each of the three scales separately $(p<.001)$. Multivariate Helmert contrast tests indicated very significant differences between the positive and the negative audience condition $(F=30.06, d f=3 / 266, p<.001)$ and between the neutral and negative audience conditions $(F=32.31, d f=3 / 266, p<.001)$. These differences were also significant $(p<.001)$ in univariate analyses. The overall difference between the neutral and the positive audience condition was also significant (multivariate analysis of variance: $F=2.99, d f=3 / 266, p<.05$ ); but in univariate analysis no significant differences were found. These differences indicate that on all three scales subjects rated the negative audience lower than the positive or neutral audience; while there were no differences between the positive and neutral audiences. However, a significant interaction effect was found for party membership and audience reactions (multivariate analyses of variance: $F=6.14, d f=6 / 532, p<.001$ ); and similarly in univariate analysis for the three scales separately $(p<.001)$. A Helmert contrast test showed that this effect could be attributed to the difference between the positive and the negative audience conditions $(F=11.61 ; d f=$ $3 / 266, p<.001$ ). The Liberal subjects rated the negative audience lower than the Socialists did; on the other hand, they rated the positive audience higher than the Socialists did. 


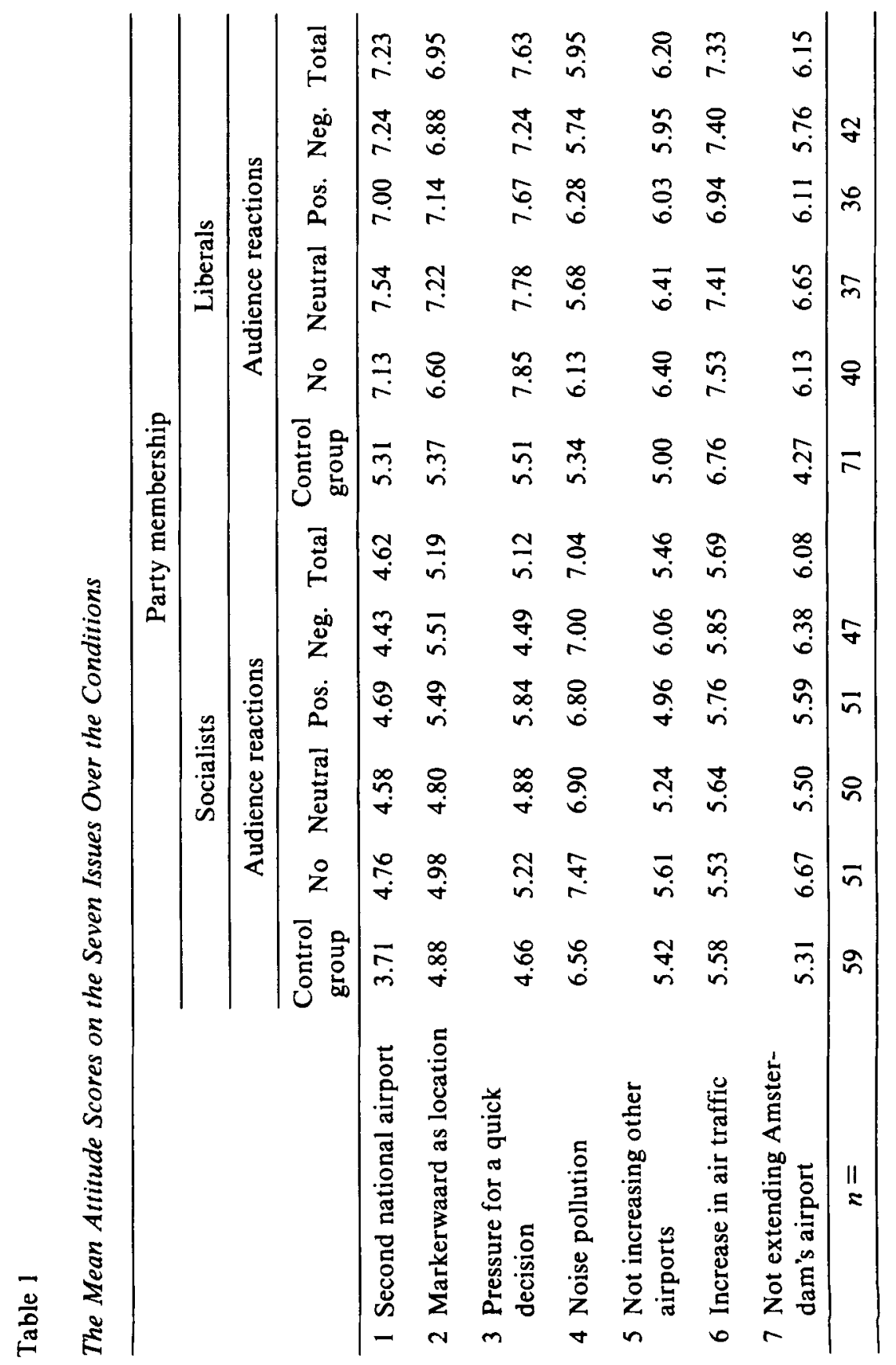




\section{Testing the Hypotheses}

In order to test our main hypothesis, a multivariate analysis of variance was performed on all the seven attitude issues, with party membership of the subjects and audience reactions as factors (Table 2 ).

A significant main effect was found for party membership (multivariate analysis of variance: $F=42.77, d f=7 / 468, p<.001$ ); and univariate analyses of variance showed a significant difference for five of the seven attitude issues (all $p<.05$ ). In the experimental conditions, the Leader of the Liberals was more able to convince the subjects who belonged to his own party than those of the Socialist party (Table 1). This result is identical to what was found in Wiegman (1985): Attitude change being greatest for the attractive source from the same party. As predicted by our main hypothesis, a significant difference between the audience conditions was found $(F=4.61, d f=28 / 1689, p<.001)$. In univariate analysis, the differences on six issues were significant. Multivariate Helmert contrast tests showed that the effect can be almost entirely attributed to the difference between the control condition (no interview) and the four experimental conditions $(F=14.87, d f=7 / 468, p<.001)$. In univariate Helmert contrast tests, significant differences between the control and the experimental conditions were found for six of the seven issues; in the experimental conditions, the mean attitude score on these issues was higher (Table 1). In other words, the presentation of the experimental interview, in itself, resulted in significant attitude change, as was found in Wiegman (1985). A tendency towards difference was found between the positive and the negative audience conditions (multivariate contrast test: $F=2.01, d f=7 / 468, p<$ .06). In univariate analysis, there was a significant difference between the two conditions only on the issue "pressure for a quick decision" $(p<.05)$. In the positive audience condition, more attitude change occurred than in the negative audience condition. This result can be seen as offering slight support for our main hypothesis that the positive audience would elicit more attitude change. On the remaining issues, no significant differences were found. Thus, in general our main hypothesis was not supported.

A significant multivariate interaction effect between party membership and audience reactions was found $(F=1.98, d f=28 / 1689, p<.01)$. In univariate analysis this interaction effect was significant for five attitude issues. However, this effect can be attributed almost entirely to the difference between the control condition and the experimental conditions. Table 1 shows clearly that the difference between the control and the experimental conditions was greater for the Liberals than for the Socialists. The multivariate Helmert contrast test was significant $(F=4.67, d f=7 / 468, p<.001)$, and in univariate analysis this interaction effect was significant for five attitude issues. In other words, the attitude change was greater for the Liberals than for the Socialists. 
Table 2

Multivariate and Univariate Analyses of Variance on the Scores of the Seven Attitude Topics (factors: party membership of the subject and audience reactions)

\begin{tabular}{|c|c|c|c|c|c|}
\hline \multicolumn{3}{|c|}{ MANOVA } & \multicolumn{3}{|l|}{ ANOVA } \\
\hline Factor & $F$ & $p<$ & Dependent variable & $F$ & $p<$ \\
\hline \multirow{7}{*}{$\begin{array}{l}\text { Party } \\
(d f=7 / 468)\end{array}$} & & & $(d f=1 / 474)$ & & \\
\hline & 42.77 & .00001 & Second national airport & 158.69 & .00001 \\
\hline & & & Markerwaard as location & 82.62 & .00001 \\
\hline & & & Pressure quick decision & 73.59 & .00001 \\
\hline & & & Not increase other airports & 3.29 & .10 \\
\hline & & & Increase in air traffic & 86.01 & .00001 \\
\hline & & & Noise pollution & 44.54 & .00001 \\
\hline \multirow{7}{*}{$\begin{array}{l}\text { Audience } \\
\text { reactions } \\
(d f=28 / 1689)\end{array}$} & & & $(d f=4 / 474)$ & & \\
\hline & 4.61 & .00001 & Second national airport & 13.06 & .00001 \\
\hline & & & Markerwaard as location & 9.99 & .00001 \\
\hline & & & Pressure quick decision & 8.26 & .00001 \\
\hline & & & Noise pollution & 2.83 & .05 \\
\hline & & & Not increase other airports & 2.84 & .05 \\
\hline & & & Amsterdam's airport & 8.74 & .00001 \\
\hline \multirow{7}{*}{$\begin{array}{l}\text { Party } \\
\times \\
\text { Audience } \\
\text { reactions } \\
(d f=28 / 1689)\end{array}$} & & & $(d f=4 / 474)$ & & \\
\hline & 1.98 & .005 & Second national airport & 2.07 & .10 \\
\hline & & & Markerwaard as location & 4.97 & .001 \\
\hline & & & Pressure quick decision & 3.30 & .05 \\
\hline & & & Not increase other airports & 2.65 & .05 \\
\hline & & & Not extending & & \\
\hline & & & Amsterdam's airport & 3.76 & .01 \\
\hline
\end{tabular}

However, when the control groups are dropped out of the analysis, the interaction effect between party membership and audience reactions was far from significant $(p<.50)$.

We also wanted to know how the source was evaluated by the subjects. The expertness, sympathy, and credibility of the source were measured on a Likert scale. A significant multivariate effect was found for the factor party member$\operatorname{ship}(F=418.26, d f=3 / 479, p<.001)$ and this effect was also significant 
for the three questions separately $(p<.001)$. The Liberals rated Wiegel as being more credible, more likable, and having more expertness than did the Socialists. No significant effect was found for the factor a udience reactions on these three scales. Another result in line with our main hypothesis was that Wiegel was evaluated as more convincing in the positive than in the negative audience condition $(F=9.22, d f=1 / 361, p<.01)$.

The alternative audience attraction hypothesis predicts more attitude change when an attractive audience expresses approval and less when it reacts negatively, while with an unattractive audience more attitude change will occur when it reacts negatively. In order to establish the audience's attraction, subjects were asked to indicate to which political party the members of the audience belonged. We regarded the audience as being attractive when subjects indicated that it belongs to their own political party and as unattractive when they indicated that it belongs to another party. Questions were asked to examine whether the audience which we considered to be attractive was actually evaluated differently by the subjects. It appeared that an audience that we consider as being attractive was perceived as significantly more correct, more likable, and more pleasant than the unattractive audience (multivariate: $F=12.52, d f=1 / 268, p<.001$; univariate for the three questions separately: $p<.001$ ). This result indicates that party similarity/difference also implies a real difference in attraction for the subjects.

Finally, to test the alternative attraction hypothesis, a multivaria te analysis of variance was carried out with the factors party membership of the subjects (2), audience attraction (2), and audience reactions (3). As predicted, a significant interaction effect between audience attraction and audience reactions was found $(F=4.83, d f=14 / 502, p<.001)$. From univariate analysis, it appeared that the interaction effect was significant for six of the seven attitude issues. Multivariate contrast tests showed that the effect can be traced to the difference between the positive and the negative audience condition $(F=8.20$, $d f=7 / 251, p<.001)$. The univariate Helmert contrast tests showed very significant differences between the positive and the negative audience condition $(p<.001)$ on five issues. With an audience, perceived as attractive, attitude change was greatest when the audience reacted positively, and least when it reacted negatively. With an audience, perceived as unattractive, the attitude change was greatest when the audience reacted negatively and least when it reacted positively. So, for most attitude issues, the alternative audience attraction hypothesis is supported. No other significant differences were found, for example, for the interaction between party membership of the subjects and audience reactions $(F=0.92, d f=14 / 502, p>.05)$.

Three questions were also asked in evaluation of the source (expertise, sympathy, and credibility). A significant interaction effect was found between audience attraction and audience reactions (multivariate: $F=7.31, d f=$ 
$6 / 520, p<.001)$. Further analysis showed that with an attractive audience, reacting positively, $\mathrm{Mr}$. Wiegel was rated higher than with an attractive audience reacting negatively. With an unattractive audience, the speaker scored higher when the audience reacted negatively than when it reacted positively. These results are also in line with the audience attraction hypothesis.

\section{Discussion}

We demonstrated that the three different ways in which the audience reacted to Wiegel affected subjects' ratings of the audience groups. The audience reacting positively or neutrally was perceived as being more correct, likable, and agreeable than the audience reacting negatively. No differences were found between the positive and the neutral audience conditions. It is noteworthy that the political preference of subjects also played an important role: Liberals perceived an audience reacting negatively as less correct, likable, and pleasant than did the Socialists, and, on the other hand, perceived the public reacting positively as more correct, likable, and pleasant than did the Socialists. Of course, this result is not surprising, as it was a Liberal leader being welcomed or criticized by the audience. It is plausible that the strong attraction to the source led the Liberals to more extreme judgments. It is of further interest to note that the Socialists, seeing their political opponent criticized by the audience, also rated this audience lower than the audience reacting positively or neutrally.

If we concentrate on attitude change, we can conclude that the experimental interview changed the opinion of the subjects in the direction advocated by the speaker. The subjects who had been exposed to the interview with the Liberal leader agreed more with the position of the speaker than those who had not seen any television program. Attitude change was greatest for the Liberals, members of Wiegel's party. This is in line with previous results (Wiegman, 1985): Attitude change being greatest for the attractive source of the same party than for the less attractive source of the opposite party.

Our main hypothesis, predicting more attitude change in the positive than in the negative audience condition, cannot in general be supported. Only on one attitude issue-concerning the pressure for a quick decision-was such a difference found. Subjects' ratings of the source, including Wiegel's credibility, did not significantly differ between the two conditions either. An exception to this was the question of the speaker's power to convince. With the audience reacting positively, Wiegel was perceived as being more convincing than when the audience reacted negatively. The negative audience seemed to undermine Wiegel's power to convince, but this apparently had no effect on attitude change.

The alternative audience attraction hypothesis, however, has mainly been 
sustained. With an audience perceived as attractive, attitude change was greatest when the audience reacted positively and least when it reacted negatively. With an unattractive audience, however, attitude change was greatest when the audience reacted negatively and least when it reacted positively. Subjects' ratings on the source were also in line with the audience attraction hypothesis. The speaker was rated higher with an attractive audience reacting positively than with an attractive audience reacting negatively; with an unattractive audience, the speaker was rated less favorably when the audience reacted positively than when it reacted negatively.

It should be noted that the political preference of the subjects and audience attraction covary because audience attraction has not and could not have been unobtrusively manipulated independently in this realistic experiment. In real life, a Liberal, for example, who perceives an audience reacting negatively to Wiegel will not readily identify them as fellow Liberals. But this is still possible, because in our country not all members of a political party react in a positive way to their political leaders; on many party meetings, these leaders often are severely criticized. Moreover, the interaction effect cannot mainly be attributed to the political preference of the subjects, because, as we have seen, the interaction effect between party membership and audience reactions was far from significant. The previous result does not prove, however, that party membership of the subjects did not play any role, nor does it mean that no other factors influenced the subjects' perception of the reacting audience, for example, one's own change in attitude.

Nevertheless, there is some evidence in support of Landy's hypothesis. We should perhaps repeat here that Landy did not, in his own study, find any support for his hypothesis. Instead he reported that, independently of the reactions of the audience, subjects were significantly more influenced by the communicator when they thought that members of an attractive audience had listened to it. He expected that if the members of an unattractive group were interested in what the speaker had to say, his credibility would be undermined and his arguments taken as more suspect. Landy's conclusion is that one means by which an individual evaluates a persuasive communication is simply by knowing who else is paying attention to what is being said. In our study, no such an effect was found, either on attitude change or on the subjects' ratings of the source.

We should bear in mind that Landy's audience had no kind of relation to the source. The audience was added after the interview and the subjects were aware of this. In our experiment, on the contrary, the audience was present and live in the studio. A certain relation between speaker and audience existed. In any case, there was an evident link, otherwise Wiegel would not have agreed to an interview with such an audience. If, as Landy claims, the mere presence of an unattractive audience undermines the credibility of the 
source and make his arguments suspect, then this should certainly have occurred in our experiment. It did not either for attitude change or for credibility of the source.

On the basis of these results, Landy's conclusion that the reactions of the audience listening to an interview are not important, and that what really matters is whether the audience is attractive or not, does not seem plausible.

\section{References}

Ajzen, I., \& Fishbein, M. (1980). Understanding attitudes and predicting social behavior. NJ: Prentice Hall.

Aronson, E., \& Golden, B. (1962). The effect of relevant and irrelevant aspects of communicator credibility on opinion change. Journal of Personality, 30, 135-146.

Bennett, E. B. (1955). Discussion, decision, commitment and consensus in "group decision." Human Relations, 8, 251-274.

Duck, S. W., \& Baggaley, J. (1975). Audience reaction and its effect on perceived expertise. Communication Research, 2, 79-85.

Fishbein, M., \& Ajzen, I. (1975). Belief, attitude, intention and behavior: An introduction to theory and research. Reading, MA: Addison-Wesley.

Horai, J., Naccari, N., \& Fatoullah, E. (1974). The effects of expertise and physical attractiveness upon opinion agreement and liking. Sociometry, $37,60 \mathrm{I}-606$.

Hovland, C. I., Janis, I. L., \& Kelley, H. H. (1953). Communication and persuasion. New Haven: Yale University Press.

Kelly, H. H., \& Woodruff, C. L. (1956). Members' reaction to apparent approval of a counternorm communication. Journal of Abnormal and Social Psychology, 52, 67-74.

Landy, D. (1972). The effect of an overheard audience's reaction and attractiveness on opinion change. Journal of Experimental Social Psychology, 8, 276-288.

Nemeth, C., \& Endcott, J. (1976). The midpoint as an anchor: Another look at discrepancy of position and attitude change. Sociometry, 39, 11-18.

Wiegman, O. (1985). Two politicians in a realistic experiment: attraction, discrepancy, intensity of delivery and attitude change. Journal of Applied Social Psychology, 15, 673-686.

Wiegman, O., \& Delfos, S. (1979). Het effect van inzicht in de experimentele situatie op aanstekelijkheid van verbaal modelgedrag. Ned. Tijdschrift voor de Psychologie, 34(3), 153-166.

Zucker, H. G. (1978). The variable nature of news media influence. In B. D. Ruben (Ed.), Communication yearbook 2 (225-240). New Brunswick, NJ: Transaction Books. 